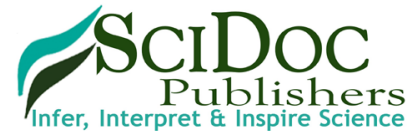

International Journal of Forensic Science \& Pathology

(IJFP)

ISSN 2332-287X

\title{
Statures of Prehistoric Humans from Fossil Femora and Humeri
}

Sankhyan $\mathrm{AR}^{1,2^{*}}$

${ }^{1}$ Sr. Anthropologist (Physical) \& Visiting Fellow, Anthropological Survey of India (Rtd.).

${ }^{2}$ President Palaeo Research Society, IPH Colony, Ghumarwin, H.P., India.

\section{Abstract}

The author has recently discovered six femoral and three humeral fossil fragments of the Stone Age humans from Central Narmada valley. The present study deals with the stature estimations of those prehistoric men by using the segment ratios and the obtained lengths of the fossil femora and the Humeri. The study is significant in forensic studies as well as in palaeoanthropology for understanding the hitherto unknown statures of prehistoric men and their biological adaptations and evolution in South Asia. The results show that very short-statured early humans inhabited the central Narmada valley between 300-70 Kya. This, couple with previous studies suggest that the short-bodied Narmada hominins constituted the ancestral stock for the subsequent similar late Pleistocene populations of South Asia, like the Munda and the pygmy of Andaman Islands, supported by the recent genomic studies that a common ancestor lived on Indian mainland around 60,000 years B.P., and these populations got differentiated about 25,000 years ago.

Keywords: Stature; Fossil; Femora; Humeri; Narmada Valley.

\section{Introduction}

In palaeoanthropological, archaeological and forensic researches we frequently encounter fragmentary long bones as the main source of evidence to establish identity of the individual. In such cases, estimation of stature from human skeletal remains has long been considered as an important medico-legal challenge and becomes the most important job. In absence of other bones like cranium or pelvis, anatomical knowledge of long bone even when only a fragment of it becomes available may help to meet that challenge through a series of estimation of length of long bone first and then reconstruction of stature of the unidentified individual. The present study is also significant in understanding human physical adaptations and evolution of man to the changing ecology of the Middle to Late Pleistocene (300-25 kya) of South Asia from the present sample of the fossilized long bones fromCentral Narmada valley. A solitary half skullcap datable to $\sim 300$ Kya was discovered in 1982 [27] which belonged to a large robust hominin akin to European Homo beidelbergensis [17]. But, we still do not know the exact body size of this Narmada hominin, which could be estimated from one of the femora [24, 25].
The body dimensions of the Narmada hominins could only be visualised by the first discovery of the postcranial fossils by this author [13-15]. There were 2-clavicles and a $9^{\text {th }}$ rib datable to around $150 \mathrm{Kya}$, and represented another fossil hominin than what was known by the skullcap. The maximum stature estimated from the clavicles was $\sim 135 \mathrm{~cm}$ and the shoulder width $30 \mathrm{~cm}$ suggesting a very 'short and stocky' hominin, which resembled those of the shortest Andman Pygmy [17]. Subsequent discovery of a left humeral diaphysis confirmed the existence of the 'shortbodied' hominins until $\sim 70$ Kya $[24,25]$. These postcranial bones shed some light on the phylogenetic affinities of the Narmada hominins, which is furthered by the present study.

It was only very recently between December 2015 and February 2016 that the author got an opportunity to re-scrutinized his Naramada fossil collection in the Anthropological Survey of India at Kolkata. He identified five more human femora and two humeri, besides two sacra in his Narmada collection. While the detailed morphometric study of the fossils in their geological setting and faunal and archaeological associations is underway, the present study reports on the hominin statures from the preserved segments of the femora and the humeri.

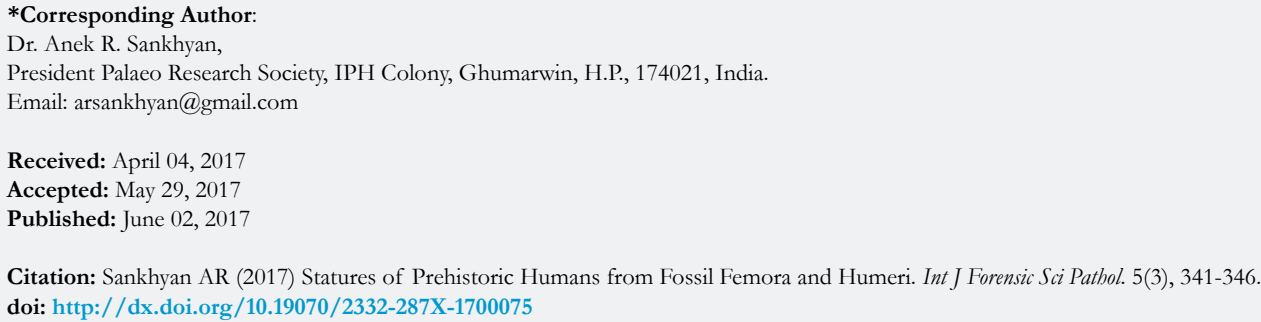

Copyright: Sankhyan $\mathbf{A R}^{\circ}$ 2017. This is an open-access article distributed under the terms of the Creative Commons Attribution License, which permits unrestricted use, distribution and reproduction in any medium, provided the original author and source are credited. 


\section{Materials And Methods}

The study material consists of six femora and three humeri shown in Figure 1 with their anatomical positions, listed below bearing their museum numbers and localities:

1. NTK-F-07-05- a left distal femur shaft from Netankheri.

2. UMR-F-08-07- a left femur distal shaft from Umaria.

3. DKC-F-05-09- a left femur distal shaft from Devakachar.

4. GRL-F-16-06 - a left femur distal shaft from Gurla.

5. HTN-F-18-05- a right proximal femur shaft from Hathnora.

6. HTN-F-45-08- a right distal femur shafts from Hathnora.

7. NTK-F-02-07- a left humeral distal shaft from Netankheri.

8. DHG-F-42-06- a left humerus midshaft from Dhanaghat.

9. BDG-F-04-07- a left humerus midshaft from Budhni.

The linear measurements were taken with a digital Mititoyo Vernier caliper and also verified by a dialMititoyo Vernier caliper. The total length of the fossil femora were estimated by using the segment proportions generated by Solan \& Kulkarni (2013) [26], whereas the humeral length was estimated by following the diaphysial segment ratios generated by Kantha \& Kulkarni (2014) [7]. Long back, Trotter \& Gleiser (1952) [29] were the first to suggest formulae for estimating the statures from the skeletal elements for Caucasian males later revised them [29], and considered to be the most reliable for Caucasian population by Stewart (1979I; Bass (1987) [28]. These still hold good at large; the formula proposed by Jungers et al., (2016) [6]: Stature $(\mathrm{cm})=[0.331 \mathrm{X}$ femur length $(\mathrm{mm})]+15.876 ; \mathrm{R}=0.89$, s e e $=3.7$ was also tested.

\section{Observations}

Various authors have demonstrated that estimation is complicated by racial differences among population samples (D wight 1894; Stevensen 1929; Dupertius \& Hadden 1951; Krogman 1962; Genoves 1967; [29]; 1958). The racial affiliation of samples must be known, and the appropriate formulae or tables used (Bass 1987). Trotter \& Gleser 1958 [29] estimated the stature of older individuals. Trotter (1970) gave formulae for the stature estimation from long bones of for femur and humerus are reproduced below.

The six Narmada femoral and three humeral fragments also briefly described here and shown in Figure 1. with their anatomical segmental positions used for estimating the total lengths of the bones and the statures of the owners.

\section{Narmada Femora}

NTK-F-07-05 - A left distal femur shaft from Netankheri: It is distal-most shaft of the fully mineralized left femur detached from the condyles. The popliteal surface is well preserved while articular surface of the patella intercondylar fossa is eroded. The specimen shows a typical cylindrical shape of the hominin femur body or corpus femoris, which broadens and flattens distally near the condylar region forming a distinct triangular popliteal surface on the posterior aspect. The lateral surface is larger and rounded compared to the relatively narrow and slightly pinched medial surface above the condyles, which flares more medially backward indicating its left laterality.

The preserved length is $8.1 \mathrm{~cm}(=60 \%)$, so the complete Segment 4 would be $13.5 \mathrm{~cm}$ when fully preserved. This would yield a 42.8 $\mathrm{cm}$ length of the femur if we use the correlation value of 3.17 for segment 4 obtained by Solan \& Kulkarni (2013) [26]. Therefore, the estimated stature comes out to be: female: $159.82 \mathrm{~cm}$ and male: $164.83 \mathrm{~cm}$; considering it male from the robustness, it may be inferred that the Netankheri individual comes from a robust archaic hominin of medium height.

UMR-F-08-07: Left Femur from Umaria: It is distal body shaft detached off the condyles. The bone shows evidence of mineralization and on the medial aspect of the upper body a small chip of the cortical bone is cut off likely due to taphonomic causes or eroded. The specimen shows a typical cylindrical shape of the hominin femoral body or corpus femoris, which broadens and flattens distally near the condylar region forming a distinct triangular popliteal surface on its posterior aspect where it is strengthened by two lips of longitudinal ridges of the linea aspera, which are quite prominent and blunt. Distally, the epiphyseo-diaphyseal condylar contact lines are more visible with their eversion in the middle towards the adductor tubercle medially.

The preserved bone $10.3 \mathrm{~cm}$ is a $66.67 \%$ part of the Segment-4, such that the complete segment 4 would be $15.45 \mathrm{~cm}$. So, it would yield total length of the femur as $49.0 \mathrm{~cm}$ following its correlation value of 3.17 [26]. Thus, the stature from this femur length cones out as: female $=129.26 \mathrm{~cm}$; male $=136.13 \pm 5 \mathrm{~cm}$. As the femur belongs to an archaic robust individual, so we may prefer a male stature of $136.13 \pm 5 \mathrm{~cm}$, which falls among the relatively medium

Figure 1. Narmada fossil femora (1-6) and humeri (7-9) and their anatomical segmental positions.
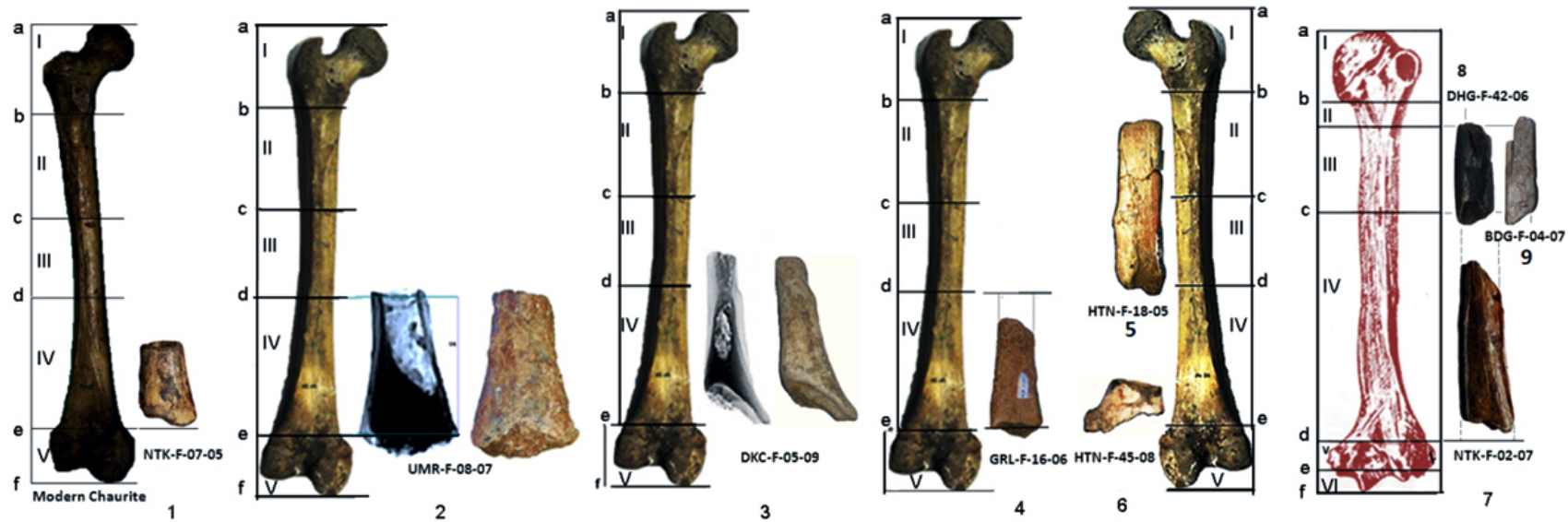
Table 1. Estimation of the Narmada fossil femoral lengths and statures from the proportions of the segment $3 \& 4$ to the respective mean total femoral lengths (TFL); the correlation value for segment- 3 is 4.18 and for Segment- 4 is 3.17 after Kantha \& Kulkarni (2014) [7]; all measurements in centimetre.

\begin{tabular}{|c|c|c|c|c|c|}
\hline Fossil Femur & $\begin{array}{c}\text { Preserved } \\
\text { Fragment }\end{array}$ & $\begin{array}{c}\text { Segment 4/3 } \\
\text { Length }\end{array}$ & TFL (x) & $\begin{array}{c}\text { Stature (Male) } \\
\mathbf{2 . 3 2} \mathbf{x + 6 5 . 5 3}(\mathbf{c m})\end{array}$ & $\begin{array}{c}\text { Stature (Female) } \\
\mathbf{2 . 4 7} \mathbf{x}+\mathbf{5 4 . 1 0}\end{array}$ \\
\hline NTK-F-07-05 & $8.1(60 \%)$ & SEG 4 13.5 & 42.8 & $\underline{164.83} \pm 5$ & $159.82 \pm 5$ \\
\hline HTN-F-18-05 & 12.8 & SEG 3 7.5 & 31.35 & $\underline{138.26 \pm 5}$ & $131.53 \pm 5$ \\
\hline HTN-F-45-08 & $2.5(25 \%)$ & SEG 4 10 & 31.7 & $\underline{139.07} \pm 5$ & $132.4 \pm 5$ \\
\hline GRL-F-16-06 & 10.5 & SEG 4 13.4 & 42.48 & $\underline{164.08 \pm 5}$ & $159.03 \pm 5$ \\
\hline DKC-F-05-09 & $11.1($ Seg 3+4) & SEG 4 9.7 & 30.75 & $136.87 \pm 5$ & $\underline{130.05} \pm 5$ \\
\hline UMR-F-08-07 & $10.6(66.67 \%)$ & SEG 9.6 & 30.43 & $\underline{136.13 \pm 5}$ & $129.26 \pm 5$ \\
\hline
\end{tabular}

Underlined value indicates for the estimated sex.

tall early modern humans.

DKC-F-05-09: Left Femur from Devakachar: It is a $12.17 \mathrm{~cm}$ long distal body shaft detached from the condyles and preserves a bit of the Segment 3, the full Segment $4(9.7 \mathrm{~cm})$ and a bit of the condylar Segment 5 intact. Proximally, a chip of the cortical bone is deeply chipped off from the medial aspect; the bone is mineralized and patinated. The specimen is typical human femur with a cylindrical body, slightly arched and more convex in front anteriorly (dorsally) and slightly concave or flattish behind (ventrally). Due to patination the surface turned featureless, and the two lips of the linea aspera are indistinct, though the mCT scan reveals the cortical thickness along the length and elliptical distal cross section. The shaft shows distinct medial flair. The anterior (dorsal) surface is smooth, convex, and slopes medially thereby broadening the lateral surface, whereas the posterior (ventral) surface is nearly rounded but slightly flattened distally in the popliteal area. The gracility of the bone and non-muscular character indicates a young adult female.

The total length may be estimated from the length of the Segment $4(9.7 \mathrm{~cm}) \times 3.17=30.75 \mathrm{~cm}$, and accordingly the mean stature of the DKC individual comes to be: female $=130.05 \mathrm{~cm}$; male $=136.87$ $\mathrm{cm}$. Hence, the DKC female hominin would be $130.05 \mathrm{~cm}$, quite 'short and stocky' hominin as found at Hathnora and Netankheri.

GRL-F-16-06: Left Femur from Gurla: It is the distal shaft detached from the condyles, proximally preserved from the point where the lateral border flares out unto the lower half of the segment-3 where the linea aspera divides into medial and lateral supracondylar lines. Distally, apart of the shaft and the condyles are detached off. The femoral body or corpus femoris has a typical cylindrical shape of the humans; it broadens and flattens (pillaster) distally near the condylar region forming a distinct triangular popliteal surface on its posterior aspect. The two lips of the linea aspera are very prominent, blunt and highly twisted and give the bone a slightly confusing triangular look like that of the proximal diaphysis of the tibia. However, the tibia is antero-posteriorly elongated and narrow, whereas femur is elongated and narrow mediolaterally and posterior surface flattish as is the specimen under reference. It has an axial twist with distinct supracondylar lines form the two ridges of the linea aspera are indicative of a very robust man with weight-bearing legs. The laterality (left side) is revealed by the larger and rounded lateral surface compared to the relatively narrow and pinched medial surface which flares more medially when the femur is held perpendicularly. The anterior surface is rounded and smooth, but posteriorly, the features are more prominent such as the deeper triangular popliteal surface enclosed by two prominent but blunt ridges of the linea aspera rising up and arching and drawing closer upwards. The lateral border is wider and convex whereas the medial border is like a narrower strip.

The specimen is heavily mineralized with visible evidence of quartz crystals inside the marrow canal and on the surface as well, and it carries the typical yellowish-brown colour of the yellow sands of the Surajkund Formation of later Middle Pleistocene.

The preserved fragment is $10.5 \mathrm{~cm}$ long, but the Segment- 4 is about $13.4 \mathrm{~cm}$. Therefore, applying the correlation value of the 3.17 [26] the total femur length comes out $3.17 \times 13.4=42.48 \mathrm{~cm}$. Hence, the mean stature of the GRL (Gurla) individual comes out to be: female $=159.03 \mathrm{~cm} \pm 5 \mathrm{~cm}$; male $=164.08 \mathrm{~cm} \pm 5 \mathrm{~cm}$. Thus, Gurla individual belongs to a very robust individual of medium height $164.08 \mathrm{~cm}$.

HTN-F-18-05: Right Femur from Hathnora: It preserves 12.8 $\mathrm{cm}$ long proximal mid-shaft, comprising a bit of the Segment 2, the full Segment $3(7.5 \mathrm{~cm})$ and a little of the Segment 4. It is mineralized and has cracks in middle and the lateral border is eroded along the pectineal curve by taphonomic agencies or gnawing by the carnivores indicated by an elongated dental depression. Proximally, the bone is broken at the base of the lesser tubercle below the lesser trochanter at its medial junction where the spiral line emanates and gives attachment to the pectineus muscle, and laterally at the gluteal tuberosity; it is the anatomically weak region liable to break. The pectineal line is distinctly curved ridge-like and forms the medial lip of the linea aspera. Dorsally it is convex and roughened by muscle lines anteriorly, and nearly cylindrical and slightly arched. The posterior (ventral) surface is typically flattened or concave and strengthened by two prominent longitudinal ridges of the linea aspera with intervening groove.

The Segment 3 with correlation value 4.18 would yield the total femur length $(4.18 \times 7.5)=31.35 \mathrm{~cm}$. Therefore, the estimated stature comes out to be: female $=131.53 \mathrm{~cm}$; male $=138.26 \mathrm{~cm}$. We may regard it a male considering the robustness of the bone, hence $138.26 \pm 5 \mathrm{~cm}$, which again falls among the 'short and stocky' individuals. 
HTN-F-45-08: Right Femur from Hathnora: It preserves only $1 / 4^{\text {th }}$ of the distal shaft, just $2.5 \mathrm{~cm}$ of the estimated $10 \mathrm{~cm}$ long Segment 4. It is mineralized and shares the colouration of the HTN-F-18-05 right femur, and likely represents its distal part from which the condyles have been detached off. The total length for the $10 \mathrm{~cm}$ long segment 4 would be $10 \times 3.17=31.7 \mathrm{~cm}$. So, the stature estimate comes to: female $=132.4 \mathrm{~cm}$; male $=139.07 \pm 5 \mathrm{~cm}$. Similarity in stature indicates that both Hathnora femur fragments are likely derived from the same individual, who was very 'short and stocky' later Middle Pleistocene hominin. Similar stature estimate came from the previous Hathnora clavicles [13-15, 17].

Jungers et al., (2016) [6] preferred pygmy standards for estimating stature of the Plio-Pleistocene fossil hominids using a formula: Stature $(\mathrm{cm})=[0.331 X$ femur length $(\mathrm{mm})]+15.876 ; \mathrm{R}=0.89$, s e $e=3.7$. But, these yielded very low and unrealistic estimates of statures for the Narmada hominins and may not hold good for the Middle to Late Pleistocene humans.

\section{Narmada Humeri}

The knowledge of the morphometric values of humerus segments is important in order to identify unknown bodies and stature and also helpful for the clinician in the treatment of proximal and distal humerus fracture. The correlation values of the humeral segments were followed after Kantha \& Kulkarni (2014) [7] for estimation of the total length from humeral segments; the humerus divided into 6 segments (Figure 1: 6-9):

a) The most proximal point of the head.

b) The most distal point of the circumference of the head.

c) The convergence of two areas of muscle attachment just below the major tubercle.

d) The lower end of the deltoid tuberosity.

e) The upper margin of the olecrannon fossa.

f) The lower margin of the olecrannon fossa.

g) The most distal point on the trochlea.

All the three Narmada humeri fragments are of the left side. The NTK-F-02-07 retains nearly the complete Segment 4, the other two (DHG-F-42-06 and BDG-F-04-07) retain Segments 3. The Segment-3 (c-d) is between the convergence of two areas of muscle attachment just below the major tubercle and the lower end of the deltoid tuberosity, whereas the Segment-4 (d-e) is between the lower end of the deltoid tuberosity and the upper margin of the olecranon fossa and is the largest segment, and therefore more reliable for estimation of the humeral length [7].

NTK-F-02-07-Left humeral distal shaft from Netankheri: It is a fully mineralized left distal shaft fragment, about $78 \%$ of the Segment $4(8.4 \mathrm{~cm})$, and the full segment could have measured about $11.0 \mathrm{~cm}$, below the radial sulcus (spiral groove) unto the upper margin of the olecranon fossa. It exhibits post-fossilization linear cracks, especially on the medial border. The specimen is cylindrical proximally, widening and turning prismatic distally. It is bounded by three borders and three surfaces, and shows a medial bend on the posterior surface, where the brachialis narrows upward and widens downward. Distally, the posterior surface is flattened and covered by the lateral and medial heads of the triceps brachia that give rise to part of the. It is relevant to know whether the NTK humerus is of an archaic hominin or of modern human. A recent study (Todd \& Churchill, 2006) shows that archaic vs modern human differentiation could be established by the proximal end of ulna, and not by the distal humerus. Nevertheless, fossilization and stout morphology may indicate a "late archaic" character of the NTK fossil humerus.

DHG-F-42-06: Left Humerus from Dhanaghat: It is almost the complete Segment 3, retaining $7.2 \mathrm{~cm}$ mid fragment of the shaft (corpus humeri) with the medullary cavity visible and reinforced at the ends. The bone fragment is about a third of the way to the elbow where the humerus swells into the deltoid tuberosity, a triangular elevation that supports the insertion point of the deltoid muscle, marked by the coraco-brachialis medially. Its upper extent is up to the mid of the pectoralis major and teres major muscular region, just below the beginning of the lateral head of the triceps. It is typically the cylindrical upper humeral body part with the lateral and medial heads of the triceps enclosing a distinct radial sulcus or the spiral groove for the radial nerve. Only a little part of the lower body is preserved which reveals the distal widening, which turns prismatic below. We can notice a medial bend or distinct twist on the posterior surface of the mid-shaft body where the brachialis narrows upward medialward and widens downward lateralward. Nearly the whole of the body surface is covered by the lateral and medial heads of the Triceps brachii, the former arising above, and the latter below the radial sulcus, a broad but shallow oblique musculospiral groove or depression. The specimen bears mineral signatures of the Surajkund Fm U2/ U3 cemented gravel showing dark colour and whitish gray patches of quartz depositions, suggesting considerable antiquity.

BDG-F-04-07: Left Humerus from Budhni: The specimen was collected from the Baneta Formation and bears its brownish gray colour of the sediments with some mineralization attesting younger Upper Pleistocene age. It is a $7.7 \mathrm{~mm}$ long mid-shaft fragment of the body shaft (corpus humeri) above the deltoid tuberosity and represents the complete Segment 3. It shows very little mid medial twist, indistinct muscular markings, slightly smaller size, more flattish posterior surface is flattish, indistinct spiral groove is; rounded and narrower lateral border.

\section{The Stature from the Humeral Fragments}

The preserved Netankheri (NTK-F-02-07) humeral fragment is $8.4 \mathrm{~cm}$, which about $78 \%$ of the complete Segment 4, estimated to be $11.0 \mathrm{~cm}$ if fully recovered. The preserved fragments of the DHG-F-42-06 and BDG-F-04-07 humeri measure 7.2 and $7.7 \mathrm{~cm}$ respectively. But, their segments 3 are complete, which measure $6.6 \mathrm{~cm}$ and $6.8 \mathrm{~cm}$, respectively. Using the proportion of the segment 3 to the total humeral length (THL) is $21.5 \%$, and of the segment 4 to total humeral length (THL) $37.3 \%$ [7]. Therefore, the computed total humeral lengths of the three Narmada humeri as well as the estimated statures from the mare given in Table 2.

\section{Discussion}

With reference to the Table 2, it may be noted that there is not much variation in the estimated humeral lengths of all the three Narmada humeri, though the Segment 3 yields slightly higher estimates of the humeral lengths. It is noteworthy that segment- 4 is the largest segment and much more reliable [7]. Considering this, the estimated humeral length of the NTK-F-02-07 segment 4 $(29.49 \mathrm{~cm})$ is near to reality and tallies with the mean length of five 
Table 2. Estimation of the humeral length, total humeral lengths of the Narmada humeri from the proportions of the segment (SEG $3 \& 4$ ) to the respective mean total humeral lengths (THL) after Kantha and Kulkarni (2014) [7].

\begin{tabular}{|c|c|c|c|c|c|}
\hline $\begin{array}{c}\text { Fossil Hu- } \\
\text { merus }\end{array}$ & $\begin{array}{c}\text { Preserved } \\
\text { SEG }\end{array}$ & $\begin{array}{c}\text { SEG L } \\
(\mathbf{c m})\end{array}$ & $\begin{array}{c}\text { THL } \\
(\mathbf{c m})\end{array}$ & $\begin{array}{c}\text { Stature (Male) } \\
\mathbf{3 . 0 8}_{\boldsymbol{x}}+\mathbf{5 4 . 1 0} \mathbf{~ c m}\end{array}$ & $\begin{array}{c}\text { Stature (Female) } \\
\mathbf{2 . 8 9} \boldsymbol{*}_{\boldsymbol{x}}+\mathbf{5 4 . 1 0}\end{array}$ \\
\hline NTK-F-02-07 & SEG 4 & $11.0^{\mathrm{t}}$ & 29.49 & $3.08 * 29.49+54.10=144.93$ & $2.89 * 29.49+54.10=139.33$ \\
\hline DHG-F-42-06 & SEG 3 & 6.6 & 30.70 & $3.08 * 30.70+54.10=148.66 \mathrm{~cm}$ & $2.89 * 30.70+54.10=142.82 \mathrm{~cm}$ \\
\hline BDG-F-04-07 & SEG 3 & 6.8 & 31.63 & $3.08 * 31.63+54.10=151.52$ & $2.89 * 31.63+54.10=145.51 \mathrm{~cm}$ \\
\hline
\end{tabular}

SEG 3L $=21.5 \%$ of THL; SEG 4L=37.3 \% of THL ([7]).

Chaurite humeri $(29.14 \pm 1.3 \mathrm{~cm})$ as well as from a larger sample of 33 mixed main land Indian including Chaurite $(28.47 \pm 2.72$ $\mathrm{cm})$. Interestingly, the Chaurite Nicobari population is shorter and stockier from the western early human populations, which includes Omo Kibish and Cro-Magnon 1 (Carretero, 2009; Bermudez de Castro et al., 2012, personal communication). Therefore, the Netankheri hominin was also quite short and stocky having $144.93 \mathrm{~cm}$ male and $139.33 \mathrm{~cm}$ female statures, which falls within the range of the Andaman negrito pygmy.

Coupled with the earlier findings of two clavicles and a rib, the NTK humerus thus, suggests that the Central Narmada Valley was continuously occupied by "short and stocky" early to late archaic or early modern Homo sapiens populations during Middle to Late Pleistocene of South Asia, and it is not unlikely they included the ancestors of similar short-bodied ancient Indians/ South Asians including the Andaman Pygmy [17, 19, 24, 25]. The other Narmada hominin humeri also present a similar picture, especially the Dhanaghat humerus; Dhanaghat is located on the bank of River Narmada opposite to Netankheri. It is likely that it was the same hominin population of the archaic short and stocky hominins whereas the Budhni hominin was relatively taller and modern.

Overall, we can observe that the Central Narmada Middle to late Pleistocene hominins were robust and short and stocky. Probably, the palaeoenvironmental scenario reconstructed by Kotlia \& Joshi (2008) [11] with prevalence of warm climatic conditions in the Narmada valley favoured 'short-bodied' hominin populations during the later Middle to Late Pleistocene. Similar inferences have also been drawn by Sankhyan (2010: unpublished). On such body adaptations, it may be reasonable to postulate that the Narmada hominins might contain the common ancestors of the 'small-bodied' later Pleistocene and Holocene ancient populations inhabiting Indian mainland, including the Andaman pygmies [16, 18, 23, 30], who also shared mtDNA signatures until their split $\sim 25 \mathrm{kya}$ [2-4]. The detailed discussion on this aspect has been attempted elsewhere in author's forthcoming book "Indian Origins".

\section{Acknowledgements}

The present study on the fossil collection housed in the Anthropological Survey of India, Kolkata was conducted between December 2015 and February 2016 by the author as Visiting Fellow. In earlier publications, he has credited the young workers involved in the field and acknowledged several scholar advisors. Here, likes to thank Shri G.S. Rautala, the then director for providing he the opportunity for study.

\section{References}

[1]. Badam GL, Sankhyan AR (2009) Evolutionary trends in Narmada fossil fauna. Asian Perspectives on Human Evolution. Serials Publications, NewDelhi. 92-102.

[2]. Barik SS, Sahani R, Prasad BVR, Endicott P, Metspalu M, et al., (2008) Detailed mtDNA Genotypes Permit a Reassessment of the Settlement and Population Structure of the Andaman Islands. Am J Phys Anthropol. 136(1): 19-27.

[3]. Chandersekar C, Rao VR (2007) Genetic Finger Printing and Peopling of Indian sub-Continent. Human Origins, Genome \& People of India: Genomic, Palaeontological \& Archaeological Perspectives. Allied Publishers Pvt Ltd., New Delhi, 15-27.

[4]. Chandrasekar A, Kumar S, Sreenath J, Sarkar BN, Urade BP, et al., (2009) Updating phylogeny of Mitochondrial DNA Macrohaplogroup M in India: Dispersal of Modern Humans in South Asian Corridor. PLoS ONE. 4(10): $1-12$.

[5]. Cameron D, Patnaik R, Sahni A (2004) The phylogenetic significance of the Middle Pleistocene Narmada hominin cranium from Central India. Int J Osteoarchaeol. 14(6): 419-447.

[6]. Jungers WL, Grabowski M, Hatala KG, Richmond BG (2016) The evolution of body size and shape in the human career. Phil Trans R Soc B. 371(1698): 20150247.

[7]. Kantha L, Kulkarni R (2014) Estimation of total length of humerus from its fragments in South Indian population. Original Article, Intl J Anat Res. 2(1): 213-20.

[8]. Kennedy KAR (2000) God-Apes and Fossil men: The Paleoanthropology of South Asia. Michigan: The University of Michigan Press.

[9]. Kennedy KAR (2007) The Narmada fossil hominid. Human Origins, Genome and People of India. New Delhi: Allied Publishers. 188-192.

[10]. Kennedy KAR, Sonakia A, Chiment J, Verma KK (1991) Is the Narmada hominin an Indian Homo erectus? Am J Phys Anthropol. 86(4): 475 - 496.

[11]. Kotlia BS, Joshi M (2008) Reconstruction of Late Pleistocene palaeoecology of the Upper Narmada valley (Central India) using fossil communities. Palaeoworld. 17(2): 153-159.

[12]. Lumley MA, Sonakia A (1985) Premiere Découverte D'un Homo erectus Sur Le Continent Indien a Hathnora, Dans la Moyennevallée de la Narmada. L'Anthropologie. 89(1): 13-61.

[13]. Sankhyan AR (1997a) Fossil Clavicle of a middle Pleistocene hominid from the CentralNarmada Valley, India. J Hum Evol. 32(1): 3-16. doi:10.1006/ jhev.1996.0117.

[14]. Sankhyan AR (1997b) A new human fossil find from the Central Narmada basin and its chronology. Curr Sci. 73(12): 1110-1111.

[15]. Sankhyan AR (2005) New fossils of Early Stone Age man from Central Narmada Valley. Curr Sci. 88(5): 704-707.

[16]. Sankhyan AR (2007) Significance of Human Post-cranial Fossils from Narmada with Remarkson the Skullcap. Human Origins, Genome and People of India. New Delhi: Allied Publishers Pvt. Ltd., 193-217.

[17]. Sankhyan AR (2010) Pleistocene hominins and associated findings from Central Narmada Valley bearing on the evolution of man in South Asia. Panjab University, Chandigarh.

[18]. Sankhyan AR (2013) The Emergence of Homo sapiens in South Asia: The Central Narmada Valley as Witness (Original scientific paper). Hum Biol Rev. 2(2): 136-152.

[19]. Sankhyan AR (2015) Pleistocene hominin fossil discoveries in India: Implications for humanevolution in South Asia. Recent discoveries and perspectives in human evolution, BAR Intl Series 2719, England: Archaeopress. 41-51.

[20]. Sankhyan AR (2016) Hominin fossil remains from the Narmada Valley. A 
Companion to South Asia in the Past. (1st Edn), New York: JohnWiley \& Sons. 72-85.

[21]. Sankhyan AR (2016) Indian Origins: Hominins \& Their Cultures in Narmada Valley, Kolkata: Anthropological Survey of India, (Submitted)

[22]. Sankhyan AR, Rao VR (2007) Did ancestors of the pygmy or hobbit ever live in Indianheartland? In: Indriati, E. (Ed.) Recent Advances on Southeast Asian Paleoanthropology and Archeology. GadjahMada University, Yogyakarta, Indonesia. 76-89.

[23]. Sankhyan AR, Sahani R (2015) The Andaman Pygmy: Origins and New Adaptations. Recent discoveries and perspectives in human evolution, BAR Intl Series 2719, England: Archaeopress. 161-171.

[24]. Sankhyan AR, Badam GL, Dewangan LN, Chakraborty S, Prabha S, et al., (2012) New postcranial hominin fossils from the Central Narmada Valley, India. Advances in Anthropology. Sci Res. 2(3): 125-131. OI:10.4236/ aa.2012.23015.

[25]. Sankhyan AR, Dewangan LN, Chakraborty S, Prabha S, Kundu S, et al., (2012) New human fossils and associated findings from the Central Nar- mada. Curr Sci. 103(12): 1-9.

[26]. Solan S, Kulkarni R (2013) Estimation of total length of femur from its fragments in South Indian Population. J Clin Diagn Res. 7(10): 2111-2115. DOI: $10.7860 / \mathrm{JCDR} / 2013 / 6275.3465$.

[27]. Sonakia A (1984) The skullcap of early man and associated mammalian fauna from Narmadavalley alluvium, Hoshangabad area, MP (India). Rec Geol Surv. India. 113: 159-172.

[28]. Stewart TD (1951) Hrdlicka's Practical Anthropometry. (4th edn), The Wistar Institute of Anatomy \& Biology, Philadelphia, 172.

[29]. Trotter M, Gleser GC (1952) Estimation of stature from long bones of American Whites and Negros. Am J Phys Anthropol. 10(4): 463-514.

[30]. VanHeteren AH, Sankhyan AR (2009) Hobbits and pygmies: trends in evolution. Asian perspectives on human evolution. New Delhi, Serials Publications. 172-187. 